\title{
Influence of Ionic Liquid Structure on Supported Ionic Liquid Membranes Effectiveness in Carbon Dioxide/Methane Separation
}

\author{
Iwona Cichowska-Kopczyńska, Monika Joskowska, Bartosz Dębski, \\ Justyna Luczak, and Robert Aranowski \\ Department of Chemical Technology, Gdansk University of Technology, ul. Narutowicza 11/12, 80-233 Gdansk, Poland \\ Correspondence should be addressed to Iwona Cichowska-Kopczyńska; kopczynska.i@gmail.com
}

Received 31 October 2012; Accepted 29 January 2013

Academic Editor: Francisco José Hernández Fernández

Copyright (C) 2013 Iwona Cichowska-Kopczyńska et al. This is an open access article distributed under the Creative Commons Attribution License, which permits unrestricted use, distribution, and reproduction in any medium, provided the original work is properly cited.

\begin{abstract}
This paper indicates the possibility of application of imidazolium ionic liquids immobilized in polymeric supports-supported ionic liquid membranes - in $\mathrm{CO}_{2}$ separation from gaseous streams (e.g., biogas). Imidazolium salts containing alkyl fluoride anions, bis(trifluoromethylsulfonyl)imide and trifluoromethanesulfonate, selectively separating $\mathrm{CO}_{2}$ were used. The permeability of $\mathrm{CO}_{2}$ through membranes was investigated under gas pressure of $30 \mathrm{kPa}$ and temperature range $283-298 \mathrm{~K}$. Permeability values occurred to be higher for ionic liquids containing bis(trifluoromethylsulfonyl)imide anion. Moreover, $\mathrm{CO}_{2}$ permeability exhibited an increase with increasing temperature for all investigated systems. Stability of supported ionic liquid membranes was studied. In total, polypropylene membrane revealed the best properties, mechanical stability and observed wettability of this support were better than for polyamide and polyvinylidene fluoride ones. Polyethersulfone supports showed similar contact angles; however, its mechanical stability was significantly lower. Obtained results allowed to evaluate the effectiveness of separation process using selected ILs and supports.
\end{abstract}

\section{Introduction}

Increasing ecological awareness and legislative changes over the last decade resulted in the development of innovative technologies for purification of exhaust gas streams and air. Due to relatively easy tuning for specific application, absorption is one of the most commonly applied methods of carbon dioxide separation. Recently, the main direction of research is finding more efficient solvents that are crucial in cost reduction of carbon dioxide capture from gas mixtures. It was demonstrated that ionic liquids (ILs) can be applied as effective solvents for such purposes [1-6]. ILs consist of large, highly asymmetric cation and small organic or inorganic anion. This structure inhibits crystallization and ensures that ILs stay in a liquid state over a wide range of temperatures. Unique properties of ionic liquids are highly desired in a physical and chemical absorption processes. They can be easily adjusted by substituting cations and anions in their structure. Still, ionic liquids present high sorption capacity, thermal stability, and negligible vapour pressure. Application of ILs as absorbents allows avoiding contamination of outlet gas streams by absorbent vapours. This advantage gives ILs huge predominance over traditional volatile organic solvents used in purification of gaseous mixtures [7-11], especially in carbon dioxide removal. An excellent media for this purpose are imidazolium ionic liquids. These compounds selectively absorb $\mathrm{CO}_{2}$ with lower coabsorption of other gases such as $\mathrm{C}_{2} \mathrm{H}_{4}, \mathrm{C}_{2} \mathrm{H}_{6}$, $\mathrm{O}_{2}$, and $\mathrm{CH}_{4}[7,12-15]$. Experimental solubility values of gases in [BMIM] $\left[\mathrm{Tf}_{2} \mathrm{~N}\right]$ (1-butyl-3-methylimidazolium bis(trifluoromethylsulfonyl)imide) expressed by Henry's constants $\mathrm{K}_{\mathrm{H}}[\mathrm{MPa}]$ at $298 \mathrm{~K}$ for $\mathrm{CO}_{2}, \mathrm{C}_{2} \mathrm{H}_{4}, \mathrm{C}_{2} \mathrm{H}_{6}, \mathrm{O}_{2}$, and $\mathrm{CH}_{4}$ are 3.4, 7.0, 9.7, 173.0, and 40.3 respectively [14, 16, 17]. Moreover, gas solubility and diffusivity of the ammonium ionic liquids is of the same magnitude as of the imidazolium ones [18]. Ionic liquids are suitable solvents for upgrading 
TABLE 1: Gas permeation values in $298 \mathrm{~K}$ described in literature.

\begin{tabular}{|c|c|}
\hline Ionic liquid & Permeation, barrer \\
\hline \multicolumn{2}{|c|}{ Carbon dioxide } \\
\hline [EMIM][TfO] & $920[24] ; 1171[21,34]$ \\
\hline$[\mathrm{EMIM}]\left[\mathrm{Tf}_{2} \mathrm{~N}\right]$ & $960 ; 1702[21,34]$ \\
\hline$[\mathrm{EMIM}]\left[\mathrm{BF}_{4}\right]$ & $9699[21,34]$ \\
\hline$[\mathrm{BMIM}]\left[\mathrm{PF}_{6}\right]$ & $500[35] ; 544[34]$ \\
\hline$[\mathrm{BMIM}]\left[\mathrm{Tf}_{2} \mathrm{~N}\right]$ & $1344[34]$ \\
\hline$[\mathrm{BMIM}]\left[\mathrm{BF}_{4}\right]$ & $200[29]$ \\
\hline$[\mathrm{HMIM}]\left[\mathrm{Tf}_{2} \mathrm{~N}\right]$ & $1136[21]$ \\
\hline \multicolumn{2}{|c|}{ Methane } \\
\hline [EMIM][TfO] & $63[34]$ \\
\hline$[\mathrm{EMIM}]\left[\mathrm{Tf}_{2} \mathrm{~N}\right]$ & $94 ; 39[34]$ \\
\hline$[\mathrm{EMIM}]\left[\mathrm{BF}_{4}\right]$ & $44[34]$ \\
\hline$[\mathrm{BMIM}]\left[\mathrm{PF}_{6}\right]$ & 40 [35]; 41 [34] \\
\hline$[\mathrm{BMIM}]\left[\mathrm{BF}_{4}\right]$ & $3[29]$ \\
\hline$[\mathrm{HMIM}]\left[\mathrm{Tf}_{2} \mathrm{~N}\right]$ & $134[34]$ \\
\hline
\end{tabular}

biogas that can be further used in industry. Upgraded biogas can be injected in the gas grid or used as vehicle fuel and eventually for electricity and heat production. Apart from 50 to $75 \%$ of methane, biogas contains about $25-45 \%$ of carbon dioxide and some amounts of hydrogen sulphide, ammonia, nitrogen, hydrogen, carbon monoxide, and oxygen. Presence of these gases results in a lower energy content of biogas per unit volume when comparing to the natural gas and therefore removal of $\mathrm{CO}_{2}$, that significantly reduces its calorific value and increases corrosion, is required in many applications.

However, the high price of ILs and toxicity remain the limitations of their application in industrial scale. Thus, membrane processes allow reducing these issues. Ionic liquids can be embedded in pores of polymer supports where they are kept by capillary forces (supported ionic liquid membrane (SILM)). Therefore, membrane technology enables decrease of solvent consumption, and in consequence, costs of separation processes are lower [19-24]. There are several membrane technologies than can be used in $\mathrm{CO}_{2}$ separation, for example, membrane contactors preventing dispersion of one phase into another [25]. There can be two kinds of contactors: parallel and cross-flow, depending on the flow direction. Cross flow contactors are considered to have some advantages over parallel contactors: higher mass transfer coefficients, lower shell-side pressure drop [26, 27]. Supported liquid membrane systems contain thin barrier of ionic liquid that enables selective permeation of $\mathrm{CO}_{2}$ and $\mathrm{H}_{2} \mathrm{~S}$ if present $[28,29]$. SILMs became a good alternative to nonporous polymer membranes due to increased gas diffusion rate [30-32]. However, some authors find polymerizing of room temperature ionic liquids as a solution for low stability of SILMs in high operating pressures [33].

Usually, scientific publications present Henry's constant values as the main parameter determining absorption of $\mathrm{CO}_{2}$ in several types of ILs (imidazolium, ammonium, pyridinium, pyrrolidinium, and phosphonium) $[2,12,14,16$, 17, 37-40]. However, taking into account the mechanisms of mass transport through the liquid membranes, Henry's constant is not the only parameter governing the possibility of solvent application in membrane separation processes. In fact, possibility of $\mathrm{CO}_{2}$ capture from gas streams is determined also by the diffusion coefficient that characterises rate of transport of gas molecules through liquid membrane. From a thermodynamic point of view, separation process in liquid membrane can be described best by the diffusion coefficient formula based on solution-diffusion model (SDM) $[32,35]$ as follows:

$$
P_{i}=D_{i} \cdot S_{i},
$$

where $D_{i}$ is diffusion coefficient $\left[\mathrm{m}^{2} / \mathrm{s}\right]$, and $S_{i}$ is solubility of gas $i$ in the membrane $\left[\mathrm{mol} / \mathrm{m}^{3} \cdot \mathrm{Pa}\right]$, and $P_{i}$ is permeation through the membrane $[\mathrm{mol} / \mathrm{s} \cdot \mathrm{m} \cdot \mathrm{Pa}]$.

One has

$$
P_{i}=\frac{J_{i} \cdot l}{\left(p_{i, f}-p_{i, p}\right)},
$$

where $J_{i}$ is molar diffusion flux of component $i$ through the membrane $\left[\mathrm{mol} / \mathrm{m}^{2} \mathrm{~s}\right], l$ is thickness of the membrane $[\mathrm{m}]$, $p_{i, f}$ is partial pressure of component $i$ in the feed stream [Pa], and $p_{i, p}$ is partial pressure of component $i$ in permeate stream [Pa].

Table 1 presents exemplary permeation values published in the literature.

Differences between permeation values can be a result of differences in operational conditions, for example, pressure, humidity of gas streams, and purity of ionic liquids used in experiments.

Literature data suggest that as a result of good solubility of $\mathrm{CO}_{2}$ and low absorption of other gases, selective absorption of $\mathrm{CO}_{2}$ from biogas and exhaust gas streams is possible [41]. Carbon dioxide/methane selectivity for [EMIM][TfO] and $[\mathrm{EMIM}]\left[\mathrm{Tf}_{2} \mathrm{~N}\right]$ reported in the literature is about 18.5 and 12 , respectively [21,34].

As pointed out by Zhao et al. the outlook for carbon dioxide capture is to study the low pressure transport in ionic liquids [42]. This research deals with the issue of low pressure separation of carbon dioxide from $\mathrm{CO}_{2} / \mathrm{CH}_{4}$ gas mixtures, like for example biogas streams. As indicated previously, high selectivity of separation enables efficient biogas upgrading using ionic liquids.

\section{Experimental}

2.1. Materials. Supported ionic liquids membranes were prepared using selected polymeric supports: GH Polypro (polypropylene) (PP), FP Vericel (polyvinylidene fluoride) (PVDF), Nylaflo (polyamide) (PA), and Supor (polyethersulphone) (PES), (Pall, Gelman Laboratory, USA). For permeation experiments PP membrane was selected in order to good wettability and low swelling as indicated in results section. Four ionic liquids were applied as a membrane phase:

1-ethyl-3-methylimidazolium bis(trifluoromethylsulfonyl)imide [EMIM] [Tf $\left.{ }_{2} \mathrm{~N}\right]$, 
TABLE 2: Physicochemical parameters of polymeric supports reported by producer.

\begin{tabular}{lcccc}
\hline Support & Density, $\mathrm{kg} / \mathrm{m}^{3}$ & Pore diameter, $\mu \mathrm{m}$ & Total porosity, $\%$ & Thickness, $\mu \mathrm{m}$ \\
\hline PP & 900 & 0.2 & 80 & 92 \\
PVDF & 1790 & 0.2 & 80 & 123 \\
PA & 1130 & 0.2 & 80 & 110 \\
PES & $1370-1510$ & 0.2 & 80 & 148 \\
\hline
\end{tabular}

TABle 3: Physicochemical properties of ionic liquids used in the experiments at $298 \mathrm{~K}$.

\begin{tabular}{lcccc}
\hline Ionic liquids & Chemical formula & Density, g/cm ${ }^{3 *}$ & Viscosity, mPa.s & $\begin{array}{c}\text { Surface tension, } \\
\mathrm{mN} / \mathrm{m}\end{array}$ \\
\hline$[\mathrm{EMIM}]\left[\mathrm{Tf}{ }_{2} \mathrm{~N}\right]$ & {$\left[\mathrm{C}_{6} \mathrm{~N}_{2} \mathrm{H}_{11}\right]^{+}\left[\left(\mathrm{CF}_{3} \mathrm{SO}_{2}\right)_{2} \mathrm{~N}\right]^{-}$} & 1.52 & 32.60 & 32.56 \\
{$[\mathrm{EMIM}][\mathrm{TfO}]$} & {$\left[\mathrm{C}_{6} \mathrm{~N}_{2} \mathrm{H}_{11}\right]^{+}\left[\mathrm{CF}_{3} \mathrm{SO}_{3}\right]^{-}$} & 1.39 & 40.40 & 37.82 \\
{$[\mathrm{BMIM}]\left[\mathrm{Tf}{ }_{2} \mathrm{~N}\right]$} & {$\left[\mathrm{C}_{8} \mathrm{~N}_{2} \mathrm{H}_{15}\right]^{+}\left[\left(\mathrm{CF}_{3} \mathrm{SO}_{2}\right)_{2} \mathrm{~N}\right]^{-}$} & 1.43 & 48.06 & 30.83 \\
{$[\mathrm{BMIM}][\mathrm{TfO}]$} & {$\left[\mathrm{C}_{8} \mathrm{~N}_{2} \mathrm{H}_{15}\right]^{+}\left[\mathrm{CF}_{3} \mathrm{SO}_{3}\right]^{-}$} & 1.29 & 74.30 & 34.67 \\
\hline
\end{tabular}

* Data provided by producer.

1-ethyl-3-methylimidazolium trifluoromethanesulfonate [EMIM][TfO],

1-butyl-3-methylimidazolium bis(trifluoromethylsulfonyl)imide [BMIM] $\left[\mathrm{Tf}_{2} \mathrm{~N}\right]$,

1-butyl-3-methylimidazolium trifluoromethanesulfonate [BMIM][TfO].

Imidazolium ionic liquids with $\left[\mathrm{Tf}_{2} \mathrm{~N}\right]$ and [TfO] anions were selected, as they exhibit very good carbon dioxide absorption in comparison to $\left[\mathrm{BF}_{4}\right],\left[\mathrm{PF}_{6}\right][14,17,43]$. All chemicals were supplied by IOLITEC, Heilbronn, Germany, with purity above $99 \%$. In order to determine the effect of chemical structure of the ionic liquids on $\mathrm{CO}_{2}$ diffusion, different alkyl chain lengths of the cations and different anions were selected.

Physical and chemical properties of polymeric supports and ionic liquids applied in experiments are presented in Tables 2 and 3 .

\subsection{Methods}

2.2.1. Viscosity, Surface Tension, and Contact Angles Measurements. Measurements of dynamic viscosity coefficient of selected ionic liquids were conducted using Brookfield Rheometer LV III. The dependence of shear stress $(\mathrm{Pa})$ on shear rate $(1 / \mathrm{s})$ was determined. Ionic liquids viscosity remains constant with increasing shear rates. Such linear relationship between shear stress and shear rate is related to newtonian character of the liquid. Surface tensions of selected ionic liquids were determined by the pendant drop method using Tensiometer Krüss DSA 10. Contact angles measurements were carried out using dynamic sessile drop method using Tensiometer Krüss DSA 10. Results are shown in Tables 3 and 4.

\subsubsection{Supported Ionic Liquid Membranes Preparation Proce-} dure. Polymer supports and ionic liquids were degassed in vacuum dryer Vacucell 55 according to procedure described in the literature [44-46]. After degassing water content in ionic liquids was determined using Karl-Fischer coulometric titration method with Metrohm $831 \mathrm{KF}$ Coulometer: [EMIM][TfO]-0.370\%, [BMIM][TfO]-0.134\%, [EMIM] [Tf $\left.{ }_{2} \mathrm{~N}\right]-0.001 \%$, [BMIM] $\left.\mathrm{Tf}_{2} \mathrm{~N}\right]-0.109 \%$. Nevertheless, ionic liquids are hygroscopic, so the water content could change during the experiments.

The literature data suggest that the small addition of water improves the performance of membrane. Carbon dioxide permeation increases when the molar fraction of water increases from 0 to 0.1 . This improvement can be attributed to increased diffusivity due to the lower viscosity of ionic liquid [47].

Degassed polymeric supports were saturated with $0.1 \mathrm{~cm}^{3}$ of ionic liquids per $1.0 \mathrm{~cm}^{2}$ of support surface. The excess of ionic liquid was removed from membrane surface using blotting paper until weight of immobilized membrane was stable. The procedure was repeated three times in order to provide complete pores saturation.

2.2.3. Determination of Supports Swelling. Swelling of supports was determined on the basis of supports thickness. Thickness was determined by optical method using epifluorescent microscope L3001 equipped with digital camera Canon Power Shot A650 SI. Membrane was placed in glass holder in $Z$ direction according to the procedure described in the literature [48]. In previous work membrane swelling after 24 hours was determined. In present paper, in order to evaluate the time period of swelling effect, data obtained after 72 and 120 hours are presented.

2.2.4. Evaluation of SILMs Stability. Mechanical resistance of membrane systems on pressure difference over the membrane was investigated in laboratory test unit presented in Figure 1. Both sides of the chamber were evacuated using vacuum pump, and inert gas was released to the feed side at a rate of $50 \mathrm{~Pa} / \mathrm{s}$. Pressure difference was recorded using pressure sensors MPX 5100DP and software using Glanguage. Experiments were conducted in 283, 288, and $298 \mathrm{~K}$. 


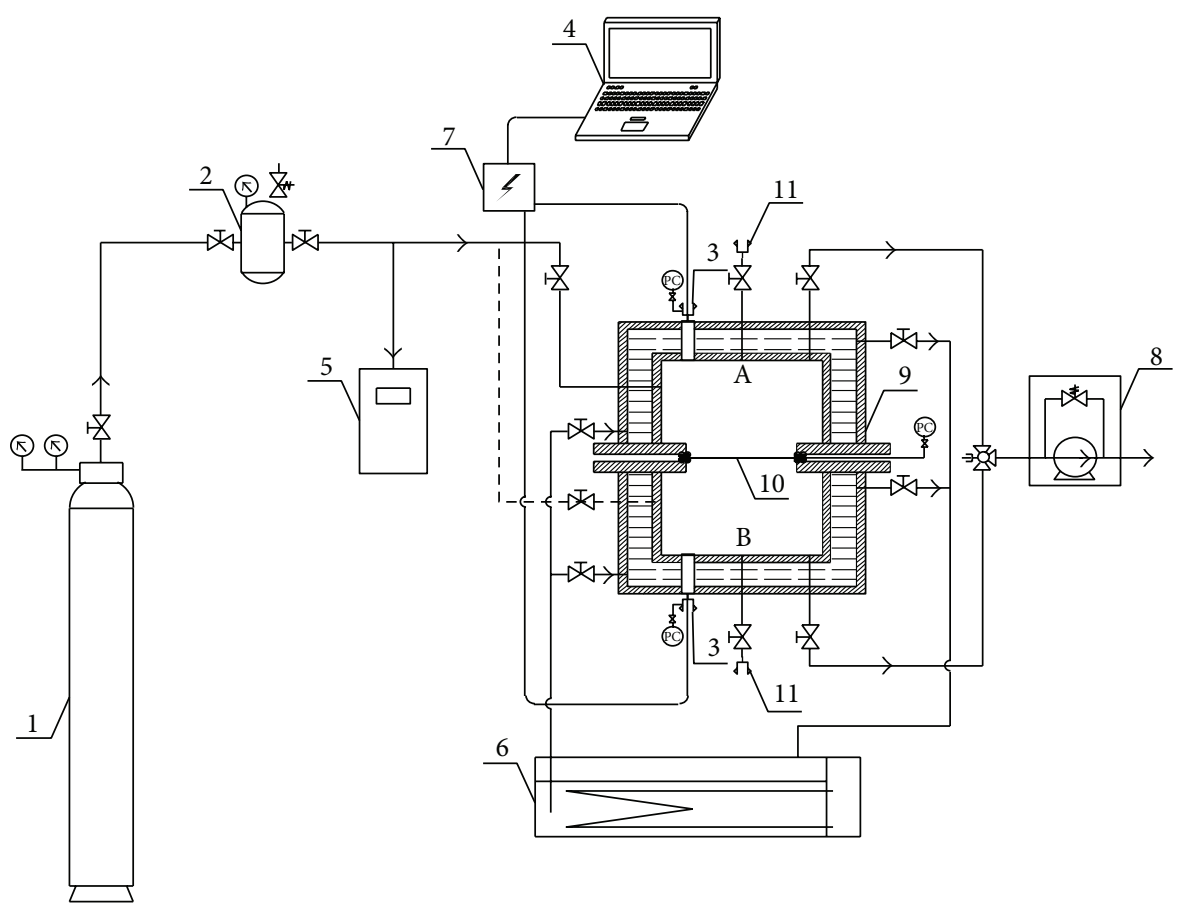

FIGURE 1: Diagram of the laboratory unit for the determination of $\mathrm{CO}_{2} / \mathrm{CH}_{4}$ permeation: $1: \mathrm{CO}_{2} / \mathrm{CH}_{4}$ gas container, 2: gas sample container, 3: pressure sensor, 4: computer, 5: $\mathrm{CO}_{2}$ analyser, 6: thermostat, 7: A/D converter, 8: vacuum pump, 9: chamber, 10: SILM, and 11: valves.

\subsubsection{Determination of Carbon Dioxide/Methane Permeation.} Permeation was determined using laboratory unit shown in Figure 1. Polymeric support saturated with ionic liquid (10) was placed in a stainless steel chamber (9), consisting of two parts: upper (feed side) and bottom (permeate side). The chamber was equipped with heating jacket coupled with thermostat (6). The experiments were carried out in 283,288 , and $298 \mathrm{~K}$ with $0.1 \mathrm{~K}$ accuracy. Both sides of the chamber were equipped with electronic temperature sensors and connected to vacuum oil pump (8). Gas container (1) was attached through differential pressure regulator with thermostatic gas sample container (2) connected to the feed part of the chamber. Pressure sensor signal (MPX 5100 DP) was transmitted to the A/D converter (7) and was recorded with software using G-language (4). The $\mathrm{CO}_{2}$ concentration in gas sample container was measured using IR analyser (5) in order to ensure that there are no other gases present in the container apart from carbon dioxide.

Experiments were carried out as the following:

(i) obtaining vacuum in feed and permeate sides (to remove $\mathrm{CO}_{2}, \mathrm{O}_{2}, \mathrm{~N}_{2}$, and other gases),

(ii) filling gas sampler (2) with $\mathrm{CO}_{2} / \mathrm{CH}_{4}$,

(iii) obtaining desirable temperature in the chamber and gas sampler containing $\mathrm{CO}_{2} / \mathrm{CH}_{4}$,

(iv) filling the feed side of the chamber with $\mathrm{CO}_{2}$ from gas sample container at a rate of $50 \mathrm{~Pa} / \mathrm{s}$, to obtain $30 \mathrm{kPa}$ pressure difference between feed and permeate side. The pressure of $30 \mathrm{kPa}$ was the maximum pressure that did not cause SILM deformation.
The drop of pressure in feed chamber and increase of pressure in permeate chamber were determined with differential pressure sensor during the experiment.

Permeation was determined on the basis of pressure difference between the feed and permeate side in time period when the pressure drop was linear.

Figure 2 presents the linear approximation of pressure difference included in (2).

Thickness of the membrane was determined before each measurement.

Application of freshly prepared SILM membrane for each experiment allowed to use the same volume of feed stream and permeate stream in every single experiment and to eliminate necessity of determination of the $\mathrm{CO}_{2}$ amount already dissolved in the ionic liquid.

\section{Results and Discussion}

3.1. Determination of Supports Swelling and Wettability. We have previously reported data on swelling of the membrane after 24 hours from immobilization procedure [36]. All the investigated supports showed higher thickness after immobilization with ionic liquid.

In present paper, data on thickness after 2, 72, and 120 hours from saturation are presented. The initial thickness of the membranes is as follows: PP $75 \pm 1$, PA $115 \pm 1$, PES $118 \pm 1$, and PVDF $160 \pm 1$. Considering data presented in Figure 3, rapid increase of thickness is observed immediately after impregnation, further differences are rather less distinct; however, the trend is preserved. Polyamide support shows similar thickness for all ionic liquids used in this study, the 
TABLE 4: Wettability of polymeric supports by ionic liquids determined by sessile drop method at $298 \mathrm{~K}$ [36].

\begin{tabular}{|c|c|c|c|c|}
\hline Ionic liquid & Support & $\begin{array}{c}\text { Advancing angle } \\
\theta_{a} \text {, deg }\end{array}$ & $\begin{array}{c}\text { Receding angle } \\
\theta_{r}, \text { deg }\end{array}$ & $\begin{array}{c}\text { Hysteresis } \\
\theta_{a}-\theta_{r}, \text { deg }\end{array}$ \\
\hline \multirow{4}{*}{ [EMIM] [Tf $\left.{ }_{2} \mathrm{~N}\right]$} & PES & $16.6 \pm 0.2$ & $9.6 \pm 0.2$ & 7.0 \\
\hline & PVDF & $12.5 \pm 0.7$ & $7.4 \pm 0.1$ & 5.1 \\
\hline & PA & $10.3 \pm 0.5$ & $6.8 \pm 0.6$ & 3.5 \\
\hline & PP & $12.3 \pm 0.5$ & $7.8 \pm 0.6$ & 4.5 \\
\hline \multirow{4}{*}{ [EMIM][TfO] } & PES & $14.5 \pm 0.6$ & $8.3 \pm 0.2$ & 6.2 \\
\hline & PVDF & $15.5 \pm 0.6$ & $8.4 \pm 0.2$ & 7.1 \\
\hline & $\mathrm{PA}$ & $14.2 \pm 0.3$ & $8.1 \pm 0.2$ & 6.1 \\
\hline & $\mathrm{PP}$ & $11.8 \pm 0.9$ & $5.6 \pm 0.7$ & 6.2 \\
\hline \multirow{4}{*}[\mathrm{BMIM}]{$\left[\mathrm{Tf}_{2} \mathrm{~N}\right]$} & PES & $16.9 \pm 0.2$ & $8.2 \pm 0.2$ & 8.7 \\
\hline & PVDF & $19.2 \pm 0.5$ & $10.9 \pm 0.5$ & 8.3 \\
\hline & $\mathrm{PA}$ & $10.7 \pm 0.4$ & $8.4 \pm 0.3$ & 2.3 \\
\hline & $\mathrm{PP}$ & $13.9 \pm 0.4$ & $8.0 \pm 0.3$ & 5.9 \\
\hline \multirow{4}{*}{ [BMIM][TfO] } & PES & $15.5 \pm 0.2$ & $8.1 \pm 0.2$ & 7.4 \\
\hline & PVDF & $18.3 \pm 0.6$ & $10.4 \pm 0.7$ & 7.9 \\
\hline & $\mathrm{PA}$ & $8.1 \pm 0.3$ & $6.6 \pm 0.1$ & 1.5 \\
\hline & PP & $10.5 \pm 0.3$ & $8.8 \pm 0.5$ & 1.7 \\
\hline
\end{tabular}

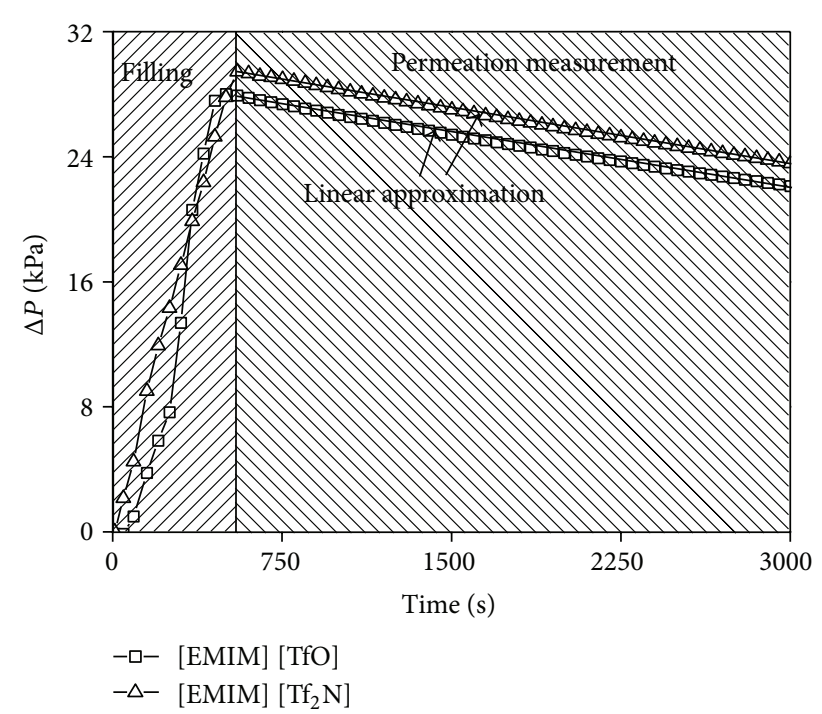

FIGURE 2: Linear approximation of pressure difference.

rate of swelling is the lowest, and it corresponds to incomplete pores saturation with the liquid, that was calculated on the basis of ratio of the real mass of IL embedded in the support pores and the theoretical value of the maximum amount of IL possible to immobilize.

Swelling of polymeric membranes can affect mechanical stability of the supports decreasing the maximum transmembrane pressure possible to apply without causing membrane damage.

The rate of swelling for all ionic liquids used in the study is similar and stays with correlation to wetting of the supports. All the values of contact angles calculated from sessile drop measurements (Table 4) were below 20 deg.,

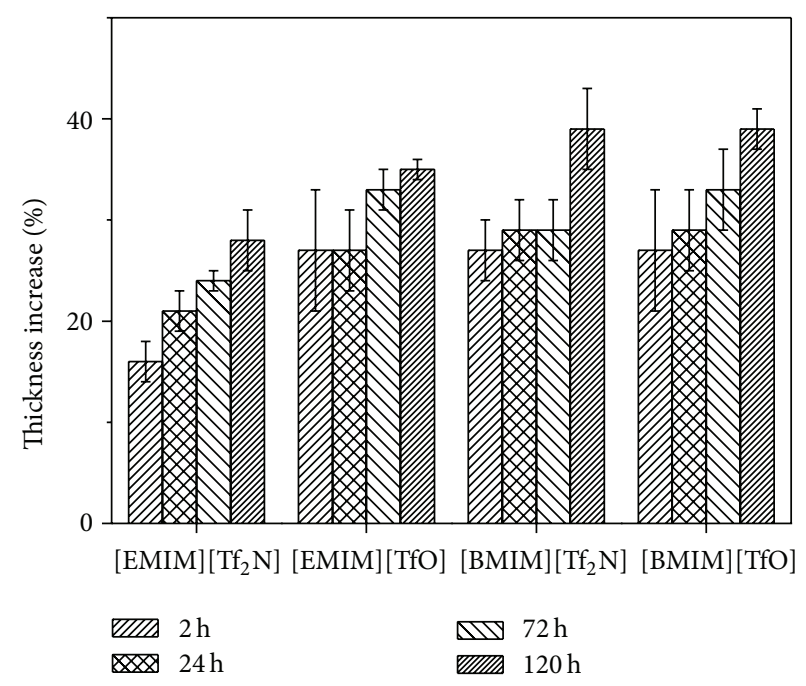

FIGURE 3: Increase of polypropylene membrane thickness.

therefore all the examined ionic liquids are suitable for perfect wetting of supports. The best wettability was observed for PA membrane, successively for PP, PVDF, and PES; however, the differences are not significant.

According to Young equation assumptions, equilibrium contact angle does not change when changing the drop volume. Supports examined in this study do not meet Young equation foundations, the drop is in the metastable state, and the hysteresis is observed. There are two components of the hysteresis value, the first one is the thermodynamic hysteresis dependent on the surface roughness and heterogeneity, whereas the second one is the dynamic hysteresis that is connected to chemical interactions of liquid and solid, 


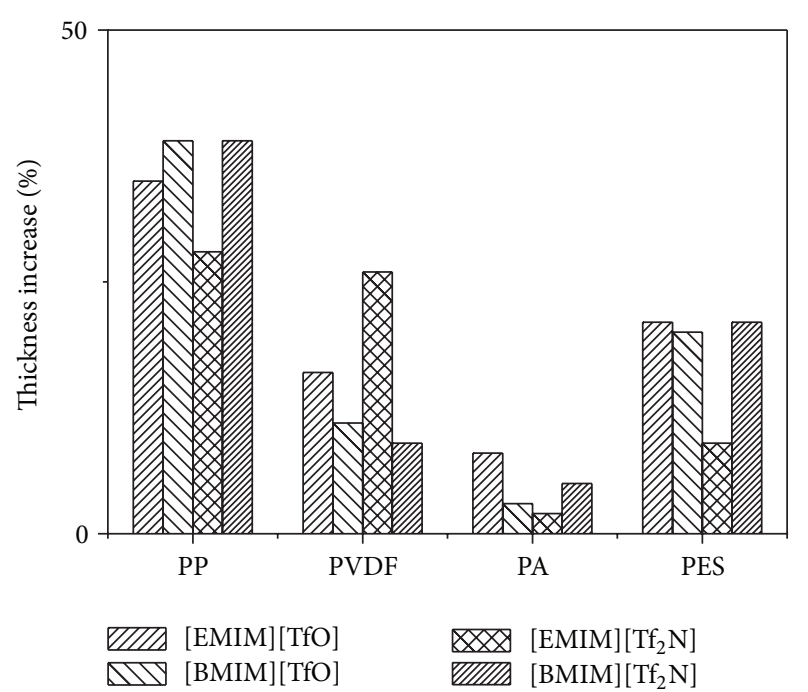

FIGURE 4: Increase of thickness of different supports saturated with ionic liquids after 120 hours.

penetration of liquid into polymer pores, and the ability of atoms or functional groups to change its positions.

The first component is not affected by the time of solidliquid drop contact, whereas dynamic hysteresis is, and moreover is dependent on the properties of polymer and ionic liquid.

Taking into account swelling of the supports, it is observed that the polypropylene membrane gains almost the same thickness immediately after impregnation for all ionic liquids used in the study, and it can be assumed that the hysteresis is dependent only on the surface roughness and heterogeneity. Further changes in thickness of the supports are connected to the liquid penetration into the pores and free space between polymer molecules and reorientation of functional groups of ionic liquids, so the particles in the ionic liquid-polymer interface reach the minimum of free interface energy. Polypropylene supports gain about 30-40\% of thickness and yet PA ones gain only about 4\% (Figure 4).

3.2. Determination of Mechanical Stability. The mechanical stability of investigated supports was determined in order to check the potential of technological application. Figure 5 presents maximum transmembrane pressure not causing polypropylene support damage. Supported ionic liquid membranes based on polypropylene support present the highest mechanical stability for operating pressures between 40 and $50 \mathrm{kPa}$. Pressure changes in course of experiment are shown in Figure 6. The peak at the curve is a result of pushing the solvent out of the pores of the support, and the gas leakage is observed. Further increase of feed stream pressure applied over the membrane leads to the polypropylene support damage, whereas for other SILMs the transmembrane pressure possible to apply without support degradation is lower than pressure required to push the impregnating liquid out of the pores. The highest pressure difference across the membrane obtained during the experiments reached $59 \mathrm{kPa}$.
Data presented in Table 5 suggest that polypropylene membrane is more stable in lower temperatures. Higher stability for PP-[EMIM][TfO] membrane stays in correlation with swelling of the membrane. Swelling rate of the PP membrane is lower for [EMIM] [TfO] than for [EMIM] $\left.\mathrm{Tf}_{2} \mathrm{~N}\right]$. Structure changes of PP impregnated with $[\mathrm{EMIM}]\left[\mathrm{Tf}_{2} \mathrm{~N}\right]$ caused lower mechanical stability of this system. However, experiments conducted in higher temperatures with different ionic liquids need to be done. Polyethersulphone membrane was damaged even if minimum pressure was applied.

In order to determine the impact of cation structure on stability of the system, polypropylene membrane was also impregnated with ionic liquids based on 1-butyl-3methylimidazolium cation. For PP-based systems, maximum pressure difference between feed and permeate side was higher when using [TfO] based ionic liquids: about $60 \mathrm{kPa}$ for [EMIM][TfO] and $48 \mathrm{kPa}$ for [BMIM][TfO], than for systems using $\left[\mathrm{Tf}_{2} \mathrm{~N}\right]$ ionic liquids as a membrane phase: $56 \mathrm{kPa}$ for [EMIM] $\left[\mathrm{Tf}_{2} \mathrm{~N}\right]$ and $46 \mathrm{kPa}$ for $[\mathrm{BMIM}]\left[\mathrm{Tf}_{2} \mathrm{~N}\right]$. The differences are not significant; however, when related to all examined temperatures, in total, membranes using ionic liquids based on [TfO] anion are slightly more stable, nevertheless it stays with a disagreement to the swelling data. However, it is likely that [TfO] anion-based ionic liquids make polypropylene more elastic enhancing the pressure resistance. The membrane is then deformed under the pressure before cracking.

The cation structure also affects mechanical properties. It can be seen that the longer hydrocarbon chain in cation structure is, the more disruptions in membrane structure occur, and the lower the mechanical stability is. Ionic liquid penetrates into the support pores and between polymer particles and fibers reorientating its structure to energetically favorable position. The longer alkyl chain length, the greater space is occupied with the ionic liquid, and the greater support expansion is observed.

Obtained results suggest that it is possible to use such SILMs without any additional mechanical supports in ventilation systems that reveal only slight pressure fluctuations. Moreover, applying SILMs to improve biogas quality directly in outlets of fermentation reactors without gas compression would also bring some profits. In many cases for the proper work of electric generators it is necessary to increase the methane content in biogas. That is why the application of SILMs is considered to be a promising perspective, especially when comparing to other methods requiring pressure increasing and regeneration of absorbent.

\subsection{Determination of Carbon Dioxide and Methane Perme-} ation. Permeability of the supported ionic liquid membranes at different temperatures is presented in Table 6. It can be seen that for each SILM system permeability increases with the increase of temperature.

Carbon dioxide permeability of the PP membrane[EMIM][TfO] system increases from 636 to 1076 barrers, as the temperature increases from 283 to $298 \mathrm{~K}$ and from 749 to 1888 barrers for PP membrane-[EMIM] [Tf $\left.{ }_{2} \mathrm{~N}\right]$ system. Temperature increase causes an increase of ions activity and 


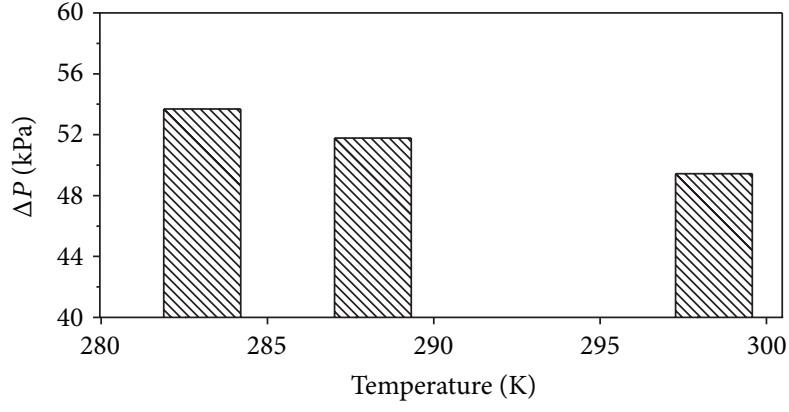

MIV [EMIM][TfO]

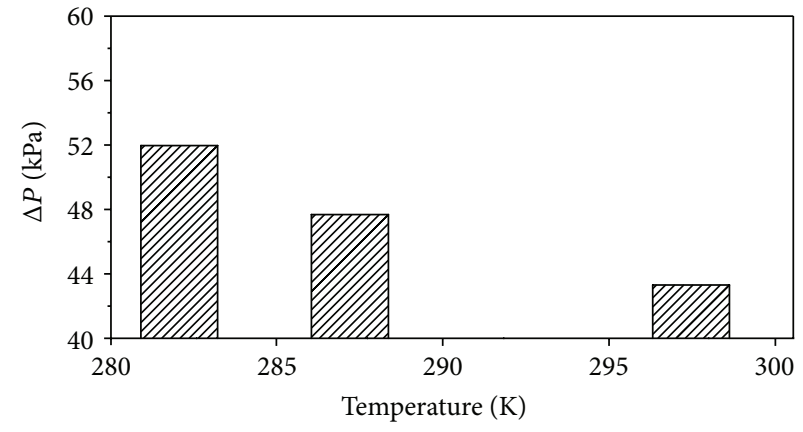

שZ] [EMIM] $\left[\mathrm{Tf}_{2} \mathrm{~N}\right]$

(a)

(b)

FIGURE 5: Maximum transmembrane pressure obtained for PP support in different temperatures.

TABLE 5: Mechanical stability of supports.

\begin{tabular}{|c|c|c|c|c|c|}
\hline Membrane & Ionic liquid & $\begin{array}{c}\text { Maximum } \\
\text { pressure } \\
\text { difference } \\
\text { obtained, } \mathrm{kPa}\end{array}$ & $\begin{array}{c}\text { Average } \\
\text { pressure } \\
\text { difference in } \\
283 \mathrm{~K}, \mathrm{kPa}\end{array}$ & $\begin{array}{c}\text { Average } \\
\text { pressure } \\
\text { difference in } \\
288 \mathrm{~K}, \mathrm{kPa}\end{array}$ & $\begin{array}{c}\text { Average } \\
\text { pressure } \\
\text { difference in } \\
298 \mathrm{~K}, \mathrm{kPa}\end{array}$ \\
\hline \multirow{2}{*}{ PES } & {$[\mathrm{EMIM}]\left[\mathrm{Tf}_{2} \mathrm{~N}\right]$} & 4.70 & $\mathrm{n} / \mathrm{a}$ & $\mathrm{n} / \mathrm{a}$ & $4.70 \pm 0.30$ \\
\hline & [EMIM][TfO] & 5.21 & $\mathrm{n} / \mathrm{a}$ & $\mathrm{n} / \mathrm{a}$ & $5.10 \pm 0.20$ \\
\hline \multirow{2}{*}{ PVDF } & {$[\mathrm{EMIM}]\left[\mathrm{Tf}_{2} \mathrm{~N}\right]$} & 22.81 & $22.14 \pm 1.05$ & $21.57 \pm 1.24$ & $20.18 \pm 1.53$ \\
\hline & [EMIM][TfO] & 21.82 & $21.10 \pm 0.63$ & $20.60 \pm 0.43$ & $20.15 \pm 0.87$ \\
\hline \multirow{2}{*}{ PA } & {$[\mathrm{EMIM}]\left[\mathrm{Tf}_{2} \mathrm{~N}\right]$} & 22.30 & $\mathrm{n} / \mathrm{a}$ & $\mathrm{n} / \mathrm{a}$ & $20.31 \pm 1.21$ \\
\hline & [EMIM][TfO] & 13.42 & $\mathrm{n} / \mathrm{a}$ & $\mathrm{n} / \mathrm{a}$ & $11.20 \pm 0.96$ \\
\hline \multirow{4}{*}{ PP } & {$[\mathrm{EMIM}]\left[\mathrm{Tf}_{2} \mathrm{~N}\right]$} & 55.75 & $51.97 \pm 3.48$ & $47.68 \pm 3.06$ & $43.31 \pm 4.77$ \\
\hline & [EMIM][TfO] & 59.53 & $53.68 \pm 1.87$ & $51.78 \pm 3.39$ & $49.43 \pm 6.23$ \\
\hline & {$[\mathrm{BMIM}]\left[\mathrm{Tf}_{2} \mathrm{~N}\right]$} & 47.64 & $46.40 \pm 1.02$ & $45.08 \pm 1.73$ & $44.59 \pm 2.89$ \\
\hline & [BMIM][TfO] & 51.78 & $50.65 \pm 1.16$ & $48.28 \pm 1.48$ & $47.07 \pm 1.00$ \\
\hline
\end{tabular}

decrease of ionic liquid viscosity and therefore an increase of $\mathrm{CO}_{2}$ permeation. According to presented data it can be concluded that the longer is hydrocarbon chain in the cation structure, the lower permeability is observed. Scovazzo et al. reported similar permeability for PES support impregnated with $[\mathrm{EMIM}]\left[\mathrm{Tf}_{2} \mathrm{~N}\right], 960$ barrers at room temperature. Ilconich et al. in their study of PS membranes immobilized with $[\mathrm{HMIM}]\left[\mathrm{Tf}_{2} \mathrm{~N}\right]$ reported a $\mathrm{CO}_{2}$ permeability 744 barrers at $310 \mathrm{~K}$ and 1200 barrers at $398 \mathrm{~K}$ [49].

It can be concluded that choosing proper polymer support is essential for obtaining satisfactory $\mathrm{CO}_{2}$ permeation. For example Baltus et al. used an inorganic ( $\gamma$-alumina) support with $[\mathrm{BMIM}]\left[\mathrm{Tf}_{2} \mathrm{~N}\right]$ and obtained significantly lower values of permeation-70 barrers [4].

Methane permeation values stay in agreement with literature data. They are significantly lower than carbon dioxide permeation values. Selectivity obtained by dividing the permeabilities of two pure gases is about 16 for [EMIM] [TfO] and 17 for [EMIM] [ $\left.\mathrm{Tf}_{2} \mathrm{~N}\right]$.

\section{Conclusions}

It has been shown that the supported ionic liquid membranes prepared with ionic liquids based on the 1-alkyl-3methylimidazolium cation are stable, especially when using polypropylene support. The effect of alkyl chain length in IL structure on the permeability was studied. The pure gas permeation results have shown that the increase in alkyl chain length and therefore increase in viscosity of ionic liquid cause the decrease in permeation values. The effect of using different ILs anions on the permeability of carbon dioxide was also evaluated, and lower permeability was observed for [TfO] anion, mainly due to higher viscosity and lower solubility of carbon dioxide. Results have also shown that the SILMs used in this study are highly $\mathrm{CO}_{2}$ selective in $\mathrm{CO}_{2} / \mathrm{CH}_{4}$ system. This fact indicated the possibility of SILMs application in selective separation of carbon dioxide, especially from gas mixtures containing methane such as biogas streams. 
TABLE 6: Permeability of carbon dioxide and methane through SILMs (with PP support) at different temperatures.

\begin{tabular}{|c|c|c|c|c|}
\hline \multirow{2}{*}{ Ionic liquid } & \multirow{2}{*}{ Temperature, K } & \multicolumn{2}{|c|}{ Permeability, barrer } & \multirow{2}{*}{ Viscosity of ionic liquid, $\mathrm{mPa} \cdot \mathrm{s}$} \\
\hline & & Carbon dioxide & Methane & \\
\hline \multirow{3}{*}[\mathrm{EMIM}]{$\left[\mathrm{Tf}_{2} \mathrm{~N}\right]$} & 283 & $749 \pm 14$ & $\mathrm{n} / \mathrm{a}$ & $56.36 \pm 1.93$ \\
\hline & 288 & $811 \pm 14$ & $\mathrm{n} / \mathrm{a}$ & $51.55 \pm 1.27$ \\
\hline & 298 & $1888 \pm 117$ & $101 \pm 1$ & $40.40 \pm 1.80$ \\
\hline \multirow{3}{*}{ [EMIM][TfO] } & 283 & $636 \pm 69$ & $\mathrm{n} / \mathrm{a}$ & $44.77 \pm 0.63$ \\
\hline & 288 & $684 \pm 31$ & $\mathrm{n} / \mathrm{a}$ & $42.26 \pm 0.61$ \\
\hline & 298 & $1076 \pm 111$ & $60 \pm 17$ & $32.60 \pm 1.07$ \\
\hline$[\mathrm{BMIM}]\left[\mathrm{Tf}_{2} \mathrm{~N}\right]$ & 298 & $936 \pm 26$ & $77 \pm 2$ & $74.30 \pm 0.71$ \\
\hline [BMIM][TfO] & 298 & $754 \pm 33$ & $43 \pm 2$ & $48.06 \pm 1.95$ \\
\hline
\end{tabular}

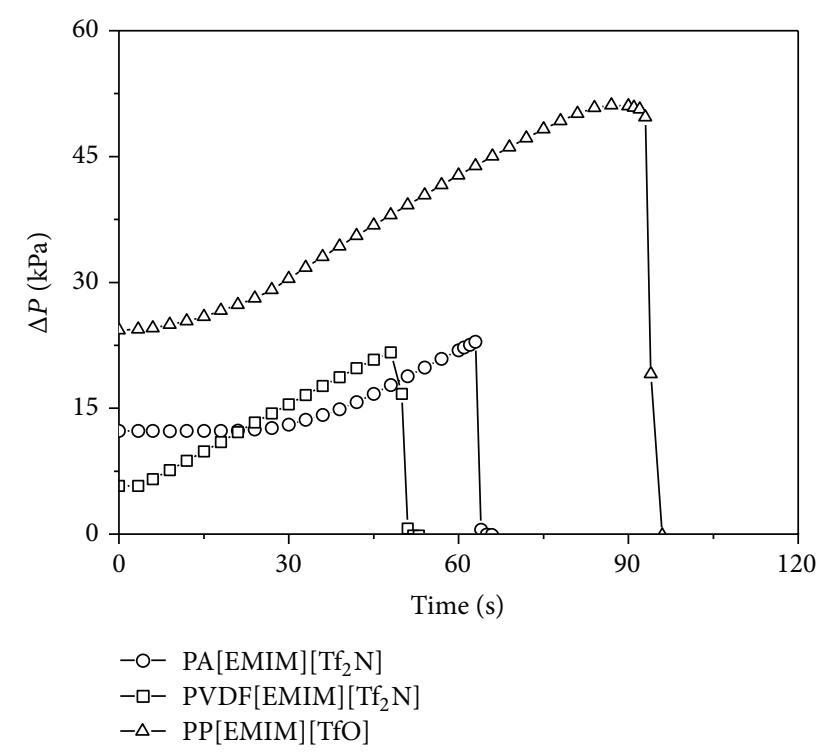

FIGURE 6: Pressure changes during stability measurements of SILMs.

SILMs systems used in this study occurred to be more stable when applying lower temperatures. When choosing proper support and type of ionic liquid, it is important to take into account properties of both. Due to interactions between them, effectiveness and lifetime of the membranes can differ significantly in connection to wettability and swelling of the support. Mechanical stability is strongly dependent on those interactions that are expressed by the rate of swelling and contact angles. Structural changes in the polymer usually result in the decrease of mechanical stability and increase of the length of permeation path. Additionally poor wetting can cause interruption of continuity of liquid membrane.

\section{Acknowledgments}

This research was supported by the National Science Centre, Grant no. 7563/B/T02/2011/40 in a title Removal of Volatile Organic Compounds from Gas Phase using Ionic Liquids. Financial support of this work was provided also by the National Centre for Research and Development of
Poland, Grant 04/strategic program/2010 about Advanced Technologies of Energy Generation, Pilot Agricultural Biogas Microstation, and Fermentation and Separation of Carbone Dioxide from Biogas with Ionic Liquids Application. The authors are very grateful for financial support provided by the Ministry of Science and Higher Education, Grant no. 1815/B/H03/2009/36.

\section{References}

[1] C. Cadena, J. L. Anthony, J. K. Shah, T. I. Morrow, J. F. Brennecke, and E. J. Maginn, "Why is $\mathrm{CO}_{2}$ so soluble in imidazolium-based ionic liquids?" Journal of the American Chemical Society, vol. 126, no. 16, pp. 5300-5308, 2004.

[2] G. Hong, J. Jacquemin, M. Deetlefs, C. Hardacre, P. Husson, and M. F. C. Gomes, "Solubility of carbon dioxide and ethane in three ionic liquids based on the bis\{(trifluoromethyl)sulfonyl\}imide anion," Fluid Phase Equilibria, vol. 257, no. 1, pp. 27-34, 2007.

[3] S. N. V. K. Aki, B. R. Mellein, E. M. Saurer, and J. F. Brennecke, "High-pressure phase behavior of carbon dioxide with imidazolium-based ionic liquids," Journal of Physical Chemistry $B$, vol. 108, no. 52, pp. 20355-20365, 2004.

[4] R. E. Baltus, B. H. Culbertson, S. Dai, H. Luo, and D. W. DePaoli, "Low-pressure solubility of carbon dioxide in roomtemperature ionic liquids measured with a quartz crystal microbalance," Journal of Physical Chemistry B, vol. 108, no. 2, pp. 721-727, 2004.

[5] E. D. Bates, R. D. Mayton, I. Ntai, and J. H. Davis, "CO 2 capture by a task-specific ionic liquid," Journal of the American Chemical Society, vol. 124, no. 6, pp. 926-927, 2002.

[6] L. A. Blanchard, Z. Gu, and J. F. Brennecke, "High-pressure phase behavior of ionic liquid/ $\mathrm{CO}_{2}$ systems," Journal of Physical Chemistry B, vol. 105, no. 12, pp. 2437-2444, 2001.

[7] J. L. Anthony, J. M. Crosthwaite, D. G. Hert, S. N. K. Aki, E. J. Maginn, and J. F. Brennecke, "Phase equilibia of gases and liquids with 1-n-butyl-3-methylimidazolium tetrafluoroborate," in Ionic Liquids as Green Solvents, pp. 110-120, American Chemical Society, South Bend, Ind, USA, 2003.

[8] K. E. Gutowski and E. J. Maginn, "Amine-functionalized task-specific ionic liquids: a mechanistic explanation for the dramatic increase in viscosity upon complexation with $\mathrm{CO}_{2}$ from molecular simulation," Journal of the American Chemical Society, vol. 130, no. 44, pp. 14690-14704, 2008. 
[9] G. Göttlicher and R. Pruschek, "Comparison of $\mathrm{CO}_{2}$ removal systems for fossil-fuelled power plant processes," Energy Conversion and Management, vol. 38, no. 1, pp. S173-S178, 1997.

[10] J. H. Edwards, "Potential sources of $\mathrm{CO}_{2}$ and the options for its large-scale utilisation now and in the future," Catalysis Today, vol. 23, no. 1, pp. 59-66, 1995.

[11] E. J. Granite and T. O'Brien, "Review of novel methods for carbon dioxide separation from flue and fuel gases," Fuel Processing Technology, vol. 86, no. 14-15, pp. 1423-1434, 2005.

[12] J. L. Anderson, J. K. Dixon, and J. F. Brennecke, "Solubility of $\mathrm{CO}_{2}, \mathrm{CH}_{4}, \mathrm{C}_{2} \mathrm{H}_{6}, \mathrm{C}_{2} \mathrm{H}_{4}, \mathrm{O}_{2}$, and $\mathrm{N}_{2}$ in 1-hexyl-3methylpyridinium bis(trifluoromethylsulfonyl)imide: comparison to other ionic liquids," Accounts of Chemical Research, vol. 40, no. 11, pp. 1208-1216, 2007.

[13] J. L. Anthony, E. J. Maginn, and J. F. Brennecke, "Solubilities and thermodynamic properties of gases in the ionic liquid 1-n-butyl3-methylimidazolium hexafluorophosphate," Journal of Physical Chemistry B, vol. 106, no. 29, pp. 7315-7320, 2002.

[14] J. L. Anthony, J. L. Anderson, E. J. Maginn, and J. F. Brennecke, "Anion effects on gas solubility in ionic liquids," Journal of Physical Chemistry B, vol. 109, no. 13, pp. 6366-6374, 2005.

[15] D. Camper, P. Scovazzo, C. Koval, and R. Noble, "Gas solubilities in room-temperature ionic liquids," Industrial and Engineering Chemistry Research, vol. 43, no. 12, pp. 3049-3054, 2004.

[16] Y. Hou and R. E. Baltus, "Experimental measurement of the solubility and diffusivity of $\mathrm{CO}_{2}$ in room-temperature ionic liquids using a transient thin-liquid-film method," Industrial and Engineering Chemistry Research, vol. 46, no. 24, pp. 81668175, 2007.

[17] E. J. Maginn, Design and Evaluation of Ionic Liquids as Novel $\mathrm{CO}_{2}$ Absorbents, University of Norte Dame, Notre Dame, Ind, USA, 2005.

[18] R. Condemarin and P. Scovazzo, "Gas permeabilities, solubilities, diffusivities, and diffusivity correlations for ammoniumbased room temperature ionic liquids with comparison to imidazolium and phosphonium RTIL data," Chemical Engineering Journal, vol. 147, no. 1, pp. 51-57, 2009.

[19] J. E. Bara, C. J. Gabriel, T. K. Carlisle et al., "Gas separations in fluoroalkyl-functionalized room-temperature ionic liquids using supported liquid membranes," Chemical Engineering Journal, vol. 147, no. 1, pp. 43-50, 2009.

[20] P. Scovazzo, J. Kieft, D. A. Finan, C. Koval, D. DuBois, and R. Noble, "Gas separations using non-hexafluorophosphate $\left[\mathrm{PF}_{6}\right]^{-}$ anion supported ionic liquid membranes," Journal of Membrane Science, vol. 238, no. 1-2, pp. 57-63, 2004.

[21] P. Scovazzo, D. Havard, M. McShea, S. Mixon, and D. Morgan, "Long-term, continuous mixed-gas dry fed $\mathrm{CO}_{2} / \mathrm{CH}_{4}$ and $\mathrm{CO}_{2} / \mathrm{N}_{2}$ separation performance and selectivities for room temperature ionic liquid membranes," Journal of Membrane Science, vol. 327, no. 1-2, pp. 41-48, 2009.

[22] Q. Gan, D. Rooney, and Y. Zou, "Supported ionic liquid membranes in nanopore structure for gas separation and transport studies," Desalination, vol. 199, no. 1-3, pp. 535-537, 2006.

[23] Q. Gan, D. Rooney, M. Xue, G. Thompson, and Y. Zou, "An experimental study of gas transport and separation properties of ionic liquids supported on nanofiltration membranes," Journal of Membrane Science, vol. 280, no. 1-2, pp. 948-956, 2006.

[24] P. Scovazzo, D. Camper, J. Kieft, J. Poshusta, C. Koval, and R. Noble, "Regular solution theory and $\mathrm{CO}_{2}$ gas solubility in room-temperature ionic liquids," Industrial and Engineering Chemistry Research, vol. 43, no. 21, pp. 6855-6860, 2004.
[25] K. Simons, K. Nijmeijer, and M. Wessling, "Gas-liquid membrane contactors for $\mathrm{CO}_{2}$ removal," Journal of Membrane Science, vol. 340, no. 1-2, pp. 214-220, 2009.

[26] V. Y. Dindore, D. W. F. Brilman, and G. F. Versteeg, "Modelling of cross-flow membrane contactors: physical mass transfer processes," Journal of Membrane Science, vol. 251, no. 1-2, pp. 209-222, 2005.

[27] J. Albo, P. Luis, and A. Irabien, "Carbon dioxide capture from flue gases using a cross-flow membrane contactor and the ionic liquid 1-ethyl-3-methylimidazolium ethylsulfate," Industrial and Engineering Chemistry Research, vol. 49, no. 21, pp. 11045-11051, 2010.

[28] S. H. Lee, B. S. Kim, E. W. Lee, Y. I. Park, and J. M. Lee, “The removal of acid gases from crude natural gas by using novel supported liquid membranes," Desalination, vol. 200, no. 1-3, pp. 21-22, 2006.

[29] Y. I. Park, B. S. Kim, Y. H. Byun, S. H. Lee, E. W. Lee, and J. M. Lee, "Preparation of supported ionic liquid membranes (SILMs) for the removal of acidic gases from crude natural gas," Desalination, vol. 236, no. 1-3, pp. 342-348, 2009.

[30] S. M. Mahurin, J. S. Lee, G. A. Baker, H. Luo, and S. Dai, "Performance of nitrile-containing anions in task-specific ionic liquids for improved $\mathrm{CO}_{2} / \mathrm{N}_{2}$ separation," Journal of Membrane Science, vol. 353, no. 1-2, pp. 177-183, 2010.

[31] D. Camper, C. Becker, C. Koval, and R. Noble, "Diffusion and solubility measurements in room temperature ionic liquids," Industrial and Engineering Chemistry Research, vol. 45, no. 1, pp. 445-450, 2006.

[32] D. Morgan, L. Ferguson, and P. Scovazzo, "Diffusivities of gases in room-temperature ionic liquids: data and correlations obtained using a lag-time technique," Industrial and Engineering Chemistry Research, vol. 44, no. 13, pp. 4815-4823, 2005.

[33] K. Simons, K. Nijmeijer, J. E. Bara, R. D. Noble, and M. Wessling, "How do polymerized room-temperature ionic liquid membranes plasticize during high pressure $\mathrm{CO}_{2}$ permeation?" Journal of Membrane Science, vol. 360, no. 1-2, pp. 202-209, 2010.

[34] P. Scovazzo, "Determination of the upper limits, benchmarks, and critical properties for gas separations using stabilized room temperature ionic liquid membranes (SILMs) for the purpose of guiding future research," Journal of Membrane Science, vol. 343, no. 1-2, pp. 199-211, 2009.

[35] S. H. Barghi, M. Adibi, and D. Rashtchian, "An experimental study on permeability, diffusivity, and selectivity of $\mathrm{CO}_{2}$ and $\mathrm{CH}_{4}$ through [bmim] $\left[\mathrm{PF}_{6}\right]$ ionic liquid supported on an alumina membrane: investigation of temperature fluctuations effects," Journal of Membrane Science, vol. 362, no. 1-2, pp. 346$352,2010$.

[36] M. Joskowska, I. Kopczynska, B. Debski, D. Holownia-Kedzia, R. Aranowski, and J. Hupka, "Wetting of supports by ionic liquids used in gas separation processes," Physicochemical Problems of Mineral Processing, vol. 48, no. 1, pp. 129-140, 2012.

[37] J. L. Anderson, J. K. Dixon, E. J. Maginn, and J. F. Brennecke, "Measurement of $\mathrm{SO}_{2}$ solubility in ionic liquids," Journal of Physical Chemistry B, vol. 110, no. 31, pp. 15059-15062, 2006.

[38] D. Camper, J. Bara, C. Koval, and R. Noble, "Bulk-fluid solubility and membrane feasibility of Rmim-based room-temperature ionic liquids," Industrial and Engineering Chemistry Research, vol. 45, no. 18, pp. 6279-6283, 2006.

[39] A. Finotello, J. E. Bara, D. Camper, and R. D. Noble, "Roomtemperature ionic liquids: temperature dependence of gas solubility selectivity," Industrial and Engineering Chemistry Research, vol. 47, no. 10, pp. 3453-3459, 2008. 
[40] P. K. Kilaru and P. Scovazzo, "Correlations of low-pressure carbon dioxide and hydrocarbon solubilities in imidazolium, phosphonium-, and ammonium-based room-temperature ionic liquids. Part 2. Using activation energy of viscosity," Industrial and Engineering Chemistry Research, vol. 47, no. 3, pp. 910-919, 2008.

[41] J. F. Brennecke and E. J. Maginn, "Purification of gas with liqid ionic compounds," United States Patent Application Publication, US. pp. 1-16, 2002.

[42] Z. Zhao, H. Dong, and X. Zhang, "The research progress of $\mathrm{CO}_{2}$ capture with ionic liquids," Chinese Journal of Chemical Engineering, vol. 20, no. 1, pp. 120-129, 2012.

[43] M. Joskowska, J. Łuczak, R. Aranowski, and J. Hupka, "Use of imidazolium ionic liquids for carbon dioxide separation from gas mixtures," Przemysl Chemiczny, vol. 90, no. 3, pp. 459-465, 2011.

[44] R. Fortunato, C. A. M. Afonso, M. A. M. Reis, and J. G. Crespo, "Supported liquid membranes using ionic liquids: study of stability and transport mechanisms," Journal of Membrane Science, vol. 242, no. 1-2, pp. 197-209, 2004.

[45] R. Fortunato, C. A. M. Afonso, J. Benavente, E. RodriguezCastellón, and J. G. Crespo, "Stability of supported ionic liquid membranes as studied by X-ray photoelectron spectroscopy," Journal of Membrane Science, vol. 256, no. 1-2, pp. 216-223, 2005.

[46] F. J. Hernández-Fernández, A. P. de los Ríos, F. Tomás-Alonso, J. M. Palacios, and G. Víllora, "Preparation of supported ionic liquid membranes: influence of the ionic liquid immobilization method on their operational stability," Journal of Membrane Science, vol. 341, no. 1-2, pp. 172-177, 2009.

[47] W. Zhao, G. He, L. Zhang et al., "Effect of water in ionic liquid on the separation performance of supported ionic liquid membrane for $\mathrm{CO}_{2} / \mathrm{N}_{2}$, J Journal of Membrane Science, vol. 350, no. 1-2, pp. 279-285, 2010.

[48] P. Izák, S. Hovorka, T. Bartovský, L. Bartovská, and J. G. Crespo, "Swelling of polymeric membranes in room temperature ionic liquids," Journal of Membrane Science, vol. 296, no. 1-2, pp. 131138, 2007.

[49] J. Ilconich, C. Myers, H. Pennline, and D. Luebke, "Experimental investigation of the permeability and selectivity of supported ionic liquid membranes for $\mathrm{CO}_{2} / \mathrm{He}$ separation at temperatures up to $125^{\circ}$ C," Journal of Membrane Science, vol. 298, no. 1-2, pp. 41-47, 2007. 

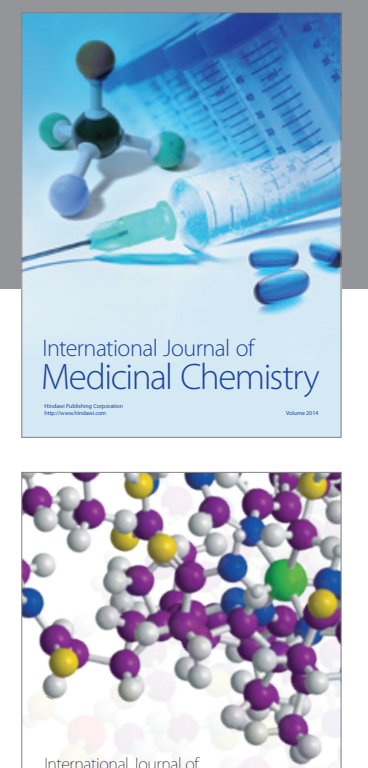

\section{Carbohydrate} Chemistry

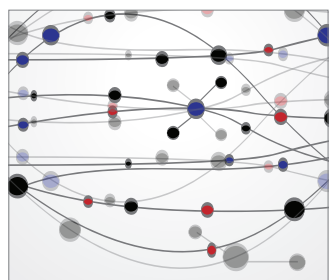

The Scientific World Journal
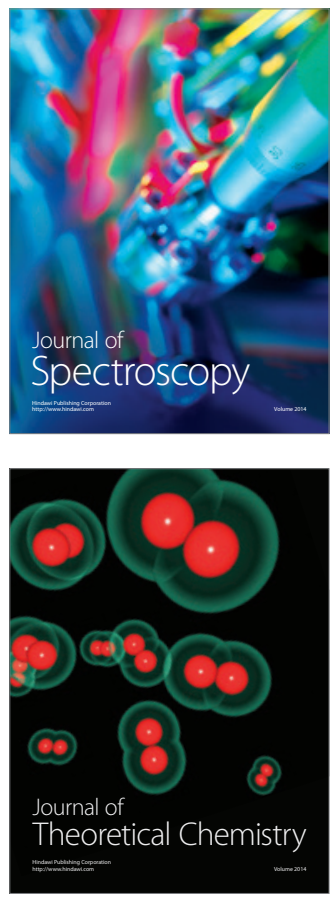
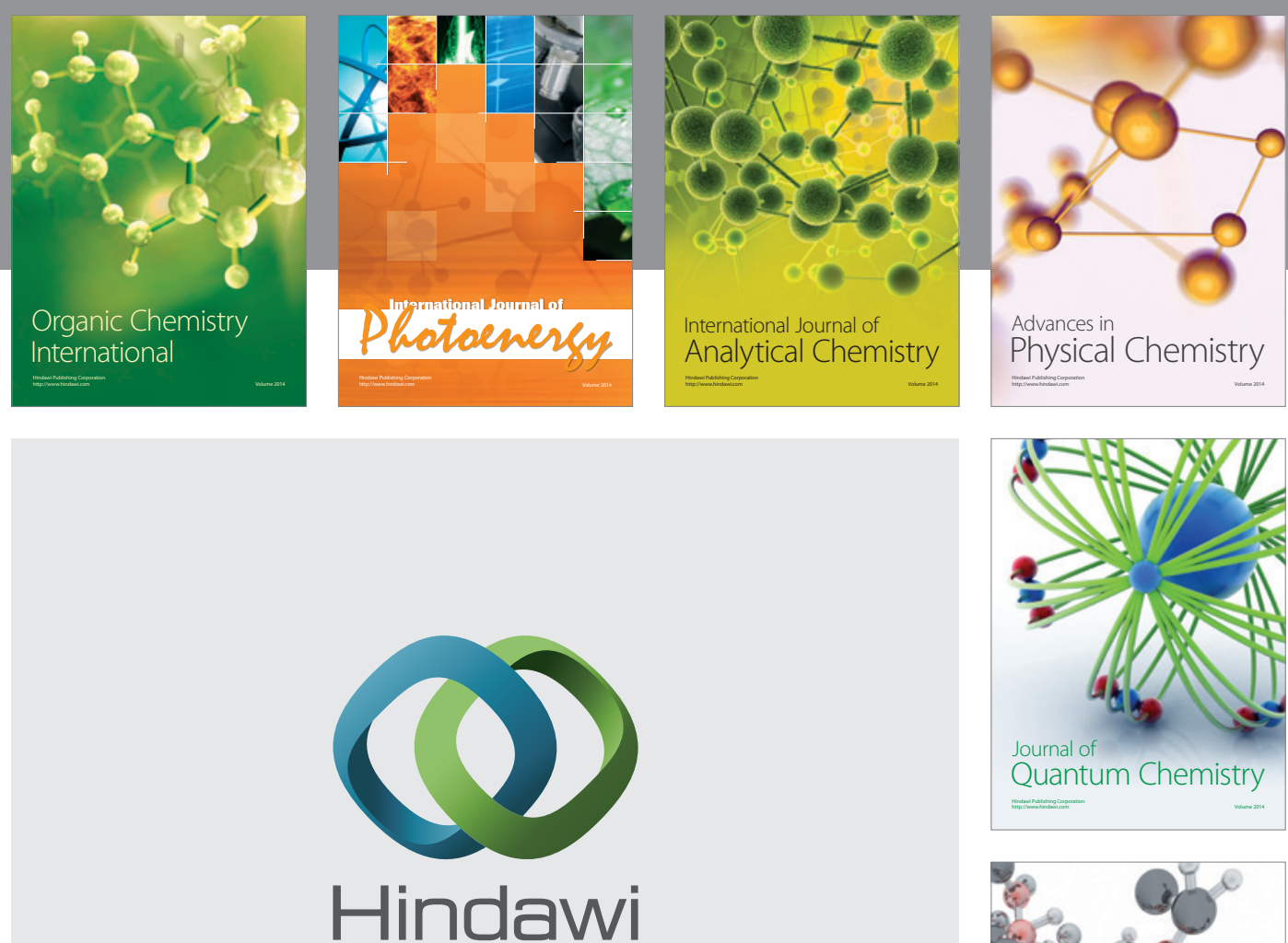

Submit your manuscripts at

http://www.hindawi.com

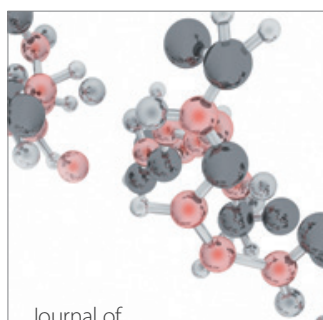

Analytical Methods

in Chemistry

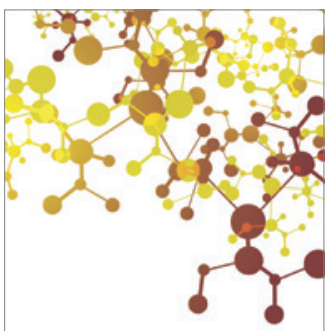

Journal of

Applied Chemistry

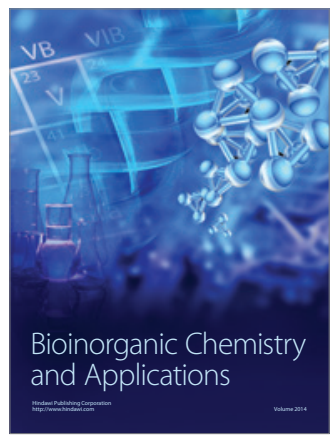

Inorganic Chemistry
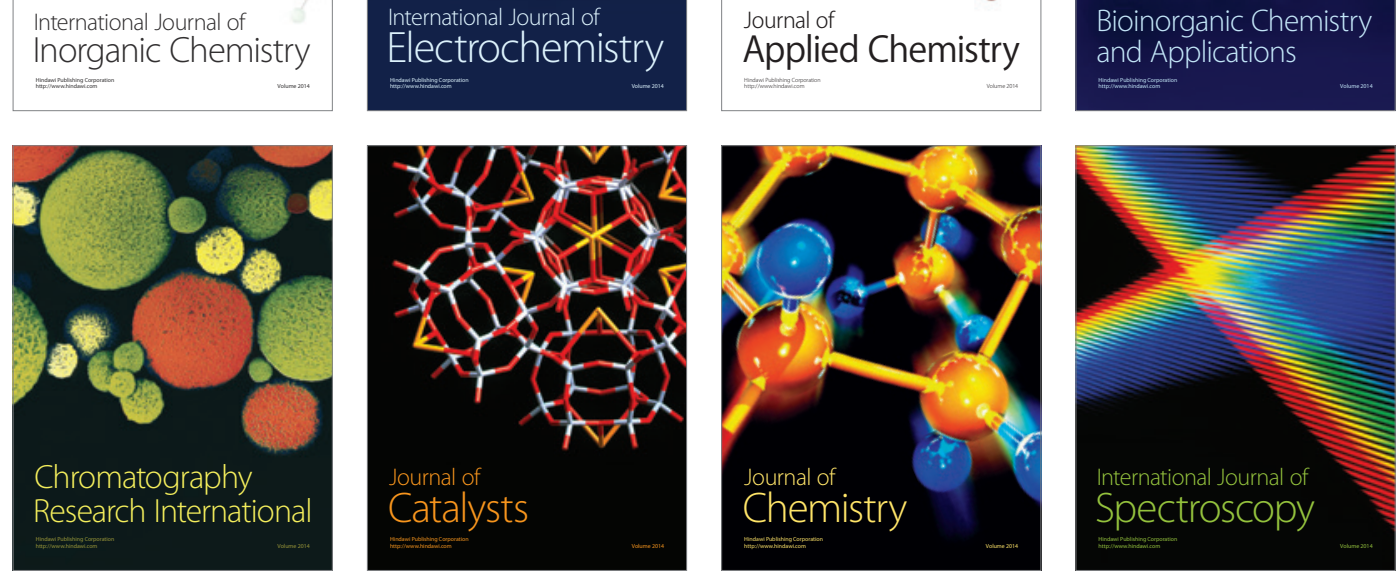